ZalǫcZnilf

DOI 10.21697/zk.2020.7.07
Uznanie autorstwa-Użycie niekomercyjne-Bez utworów zależnych

3.0 Polska (CC BY-NC-ND 3.0 PL)

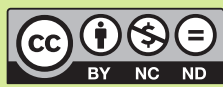

Załącznik Kulturoznawczy 7/2020

TEMAT NUMERU 1: HITCHCOCK - ROZCHYLANIE KURTYNY (W 40. ROCZNICE ŚMIERCI REŻYSERA)

\title{
NIE TYLKO REKLAMA. ARTYSTYCZNY STATUS ZWIASTUNA FILMOWEGO (W KONTEKŚCIE PSYCHOZY ALFREDA HITCHCOCKA)
}

AnNa GóRnY

Instytut Nauk o Kulturze UŚ

Institute of Cultural Studies, University of Silesia in Katowice

anna_gorny@onet.pl

ORCID: 0000-0001-9075-4962

Zwiastuny filmowe zwykle się lekceważy i traktuje wyłącznie jako dodatki do głównych tekstów artystycznych, jakimi są filmy. Ich „ulotny” status dodatkowo wzmacnia przekonanie, że zwiastun ma za zadanie jedynie utorować drogę pełnoprawnemu dziełu. Wszechobecna reklama filmowa sytuuje zwiastun w dyskursie komercji, co dalece odbiega od artystycznych aspiracji kina. Tożsamość filmowa zwiastuna i jego wartość artystyczna giną w retoryce komercyjnej, która go otacza i pomaga mu zaistnieć. W przeciwieństwie do filmu czy programu telewizyjnego zwiastun bywa redukowany do formy efemerycznego, anonimowego, niejako przejściowego gatunku medialnego, którego istnienie jest tradycyjnie definiowane przez okoliczności czasoprzestrzenne. Zwiastuny stanowią oczywiście formę reklamy, ale - zauważmy - są one jednocześnie krótkimi utworami audiowizualnymi, które można oceniać także w kategoriach artystycznych. Interpretacja wybranych zwiastunów dzieł Alfreda Hitchcocka może być dobrym sposobem na wykazanie statusu artystycznego tych krótkich form, zapowiadających filmowe całości, i zakotwiczenia ich w szerszym polu kultury audiowizualnej.

Doskonałym przykładem zwiastuna, który sam w sobie stanowi ciekawą artystycznie wypowiedź, przełamującą tradycyjne schematy, jest zrealizowany przez Hitchcocka trailer do Psychozy (Psycho, 1960). Zwiastun ten, opisany jako studium przypadku w dalszej części artykułu, zawiera cechy, które najpełniej prezentują podejście interesującego nas tu reżysera do tekstów promocyjnych. Odmienny od typowej reklamy, daje się rozpatrywać w kontekście teorii kina autorskiego, stanowiąc być może jednocześnie ilustrację niektórych tez Gilles’a Deleuze’a (kino: obraz - czas) czy Davida 
Bordwella (teoria narracji), co pomaga umiejscowić tę ulotną formę w szerszym dyskursie filmoznawczym.

Zwiastun powszechnie utożsamiany jest z reklamą. W perspektywie reguł gatunku zwiastun ma ograniczone funkcje jako tekst perswazyjny i manipulujący publicznością. Według Encyklopedii kina pod redakcją Tadeusza Lubelskiego zwiastun to „krótki film reklamowy, zapowiadający najczęściej pełnometrażowy film fabularny, wchodzący na ekrany kin, złożony z dynamicznie zmontowanych najatrakcyjniejszych jego fragmentów, informacji o realizatorach i obsadzie, często opatrzony także sloganami reklamowymi"2. W literaturze przedmiotu zwiastuny ujmuje się najczęściej jako krótkie i skierowane na przekonywanie filmy ${ }^{3}$, propagandę, reklamę filmową ${ }^{5}$ albo „eskortę filmu kinowego"6. Poza problemami definicyjnymi badania teoretyczne im poświęcone skupiały się na ich celach perswazyjnych i wpływie na publiczność. Mary Beth Haralovich i Cathy Root Klaprat opisują zwiastun jako „opowieść o 90-minutowym filmie,

1 Zob. F.L. Greene, K.M. Johnston, E. Vollans, Would I Lie to You? Researching Audience Attitudes to, and Uses of, the Promotional Trailer Format, „International Journal of Media \& Cultural Politics" 2014, Vol. 10, https://ueaeprints.uea. ac.uk/49025/1/MCP_10_1_109_116_Researching_Audience_Attitudes_to..._ Promotional_Trailer_Format_.pdf [dostęp 30.03.2020].

2 Encyklopedia kina, red. T. Lubelski, wstęp A. Wajda, Biały Kruk, Kraków 2003.

3 Zob. L. Kernan, Coming Attractions: Reading American Movie Trailers, University of Texas Press, Austin 2004, s. 1.

4 Zob. F. Greene, Working in the World of Propaganda: Early Trailers \& Modern Discourses of Social Control, „Frames Cinema Journal” 2013, Vol. 3, http://framescinemajournal.com/article/working-in-the-world-of-propaganda-early-trailers-modern-discourses-of-social-control/ [dostęp 30.03.2020].

5 Zob. S. Blandford, B. Grant, J. Hillier, The Film Studies Dictionary, Hodder Headline Group, London 2001; I. Konigsberg, The Complete Film Studies Dictionary, Bloomsbury, London 1998.

6 Zob. T. Miczka, O zmianie zachowań komunikacyjnych: konsumenci $w$ nowych sytuacjach audiowizualnych; cyt. za: I. Loewe, Parateksty $w$ telewizji, [w:] Pogranicza audiowizualności, red. A. Gwóźdź, Kraków [cop. 2010], s. 133. 
zawartą w 90-sekundowym materiale”. Zdaniem autorek zwiastuny „są rodzajem strategii reklamowej przemysłu filmowego, są także dyskursem, dzięki któremu instytucja kina zapewnia sobie zbyt"8. Według Haralovich i Klaprat „zwiastuny są konstruowane z serii przerwań odczuwalnej ciągłości narracyjnej, poprzez burzenie liniowości związków przyczynowych, [...] w zwiastunach momenty niestabilności narracyjnej są na pierwszym planie, [...] wysuwane są momenty napięcia narracji" ". Zerwanie linearności tworzy niestabilność przestrzeni i czasu narracji, budowaną przez akcentowanie zagadek i konfliktów. Jednym z ciekawszych przykładów tworzenia nieciągłości jest sposób użycia w zwiastunach grafiki (napisy, rolety), dostarczającej materiału objaśniającego, wiążącej ze sobą przestrzeń i czas ${ }^{10}$.

Studia Lisy Kernan powiązały także strukturę narracyjną z wpływem na publiczność. Badaczka postawiła tezę, że struktura narracyjna zwiastuna jest potężną formułą perswazyjną, umożliwiającą publiczności stworzenie fikcyjnego, jeszcze niewidzianego filmu z jego fragmentów - nie pragniemy rzeczy wistego filmu, ale tego, który chcemy zobaczyćl ${ }^{11}$. Ograniczenie zwiastunów do kilku minut starannie wybranych i zmontowanych migawek scen nadaje temu, co widzimy, rys wymowności i zarazem nieokreśloności, co umożliwia widowni tworzenie wyobrażonego filmu na bazie pokazanych fragmentów. To wypełnianie zwiastunowych zagadek wyidealizowanym filmem zwiększa marketingową wartość zwiastunów ${ }^{12}$. Kernan, omawiając szereg chwytów perswazyjnych stosowanych w zwiastunach, wskazuje na wykorzystywanie kodów narracji lektorskiej (voice-over narration), nakładanie się na siebie dźwięku (sound overlapping), muzyki i grafiki; co najważniejsze, akcentuje montaż (montage) oraz edycję (editing), a ściślej: edycję nieciągłości (discontinuity editing) - działającą zgodnie ze schematami wymienności, łączenia i skracania scen tak, aby skonstruować nową logikę

7 M.B. Haralovich, C.R. Klaprat, Marked Woman i Jezebel: widz w zwiastunie, tłum. P. Piekarski, [w:] Sztuka filmowej interpretacji, red. W. Godzic, Kraków 1990, s. 179.

8 Ibidem.

9 Ibidem, s. 180.

10 Ibidem, s. 179-181.

${ }_{11}$ Zob. L. Kernan, op. cit., s. 13.

12 Ibidem. 
zwiastuna, różniącą się od logiki narracyjnej filmu, choć oczywiście z nią powiązaną. Szybkie tempo większości zwiastunów podkreśla powierzchniową warstwę filmu, która jest spektaklem kinematograficznym ukazującym najatrakcyjniejsze obrazy, nadając mu status towaru na sprzedaż $\dot{z}^{13}$.

Nie sposób przecenić marketingowej roli zwiastuna filmowego, gdyż ze swej istoty stanowi on kompilację scen, obrazów, dźwięków czy animacji uwypuklających najatrakcyjniejsze elementy dzieła. Niewątpliwie, jak zauważa również Kernan, analiza zwiastunów jako swoistej formy kinematograficznej może przynieść większą świadomość krytyczną ich potencjału artystycznego:

[...] jako teksty zarówno narracyjne, jak i promocyjne, same zwiastuny można widzieć jako artystyczny rodzaj hybrydowy w ramach kanonu filmu hollywoodzkiego. Oferują one widzom eliptyczną i enigmatyczną przestrzeń opowieści, pisaną kursywą, atrakcyjnie zrekonfigurowaną, gdzie elementy takie jak gesty i spojrzenia postaci, relacje przestrzenne, ruchy postaci i kamery, dialogi i narracja, muzyka i przywoływanie struktury narracyjnej filmu mają szczególne znaczenie ${ }^{14}$.

Ulotność formatu reklamowego sprawia, że analiza krytyczna czy akademicka pochyla się nad zwiastunem jedynie przez krótką chwilę, ale on sam opiera się tym uprzedzeniom - inaczej niż inne reklamy - często demonstrując cechy filmowe i artystyczne, które wykraczają poza doraźność. Pominięcie aspektu tekstowego zwiastuna kosztem związanej z nim, jak to określa Jonathan Gray, „spekulatywnej konsumpcji” (speculative consumption) prowadzi do zatracenia dużej części jego wartości filmowej ${ }^{15}$.

Daniel Hesford zwraca uwagę, że estetyczny i przemijający charakter zwiastuna jako przedmiotu przeżycia artystycznego nie jest zjawiskiem nowym. Krótkie formy fikcji literackiej i filmowej poddają się analizom krytycznym. Literackie mikroformy, takie jak chociażby Fikcje Jorge Luisa Borgesa, podkreślają rolę autora i jego umiejętności, a także wskazują na „pomnażanie

${ }_{13}$ Ibidem.

${ }_{14}$ Ibidem, s. 7-8. Jeśli nie zaznaczono inaczej, wszystkie tłumaczenia pochodzą od autorki artykułu.

15 Zob. J. Gray, Show Sold Separately: Promos, Spoilers and Other Media Paratexts, New York 2010, s. 24. 
inwencji i wyobraźni w literaturze"16. Co więcej, według Hesforda, odchodząc od wąsko rozumianych granic filmoznawstwa, warto obecnie wziąć pod uwage zwiastuny oraz wszystko to, co badacze określają mianem „paratekstów” (termin zaproponowany przez Gérarda Genette’a na określenie elementów, które funkcjonują wokół tekstu właściwego ${ }^{17}$ ), by zrozumienie miejsca kina w kulturze wizualnej było pełniejsze ${ }^{18}$. Miniaturyzacja filmu i wszechobecność mediów, zatapianie się spójnej narracji poszczególnych utworów w audiowizualnym strumieniu reklam, zwiastunów, atrakcjonów i ekranów - jak zauważa Rafał Syska - pozwalają przyjąć założenie, iż nie powinniśmy postrzegać filmu jako samoistnego dzieła, jest on bowiem produktem stale obudowywanym tekstami pobocznymi, fragmentem szerszego hipertekstu i źródłem dla licznych dzieł wtórnych ${ }^{19}$.

Poszerzenie granic filmoznawstwa staje się faktem. Objęcie nimi również paratekstów skutkuje intensyfikacją prac badawczych m.in. nad zwiastunami, co w sposób naturalny obejmuje analizę współczesnych dokonań, ale i sięgnięcie do historii - klasyki kina. Zwiastuny filmowe mogą zatem również odegrać rolę w kulturowej i akademickiej obecności kina - ignorować czy pomijać zwiastuny tylko dlatego, że są krótkie, redukować je wyłącznie do roli służebnej względem dzieła, które promują, oznacza pomijać ważną część historii kina.

Zwiastuny Alfreda Hitchcocka, w opinii Graya, przedstawiają sobą „korpus tekstów ukazujący potencjalnie samoświadome i afektywne cechy przestrzeni promocyjnej, stanowiąc jednocześnie okazję do przedstawienia teoretycznych, istotnych dla tej kwestii, terminologii i koncepcji"20. Hitchcock nie ograniczał się do tworzenia filmów pełnometrażowych, jego aktywność rozciągała się także na telewizję, radio oraz zwiastuny filmowe,

${ }_{16}$ Zob. G.H. Bell-Villada, Borges and His Fiction: A Guide to his Mind and Art, Chapel Hill 1981, s. 41; cyt. za: D. Hesford, The Art of Anticipation: The Artistic Status of the Film Trailer and its Place in a Wider Cinematic Culture, Edinburgh 2013, s. 2.

17 Zob. G. Genette, Paratexts. Thresholds of Interpretation, New York 1987, s. $344,347$.

18 Zob. D. Hesford, op. cit., s. 2.

19 Zob. R. Syska, Nie-film, nie-kino, „Ekrany” 2016, nr 5.

20 Zob. D. Hesford, op. cit., s. 2. 
promocyjnie powiązane z reżyserowanymi przez niego obrazami. Zwiastuny te, produkowane łącznie z filmami, są godne uwagi głównie dlatego, że ustanawiały nowe techniki retoryczne, dotąd raczej niespotykane w dyskursie promocyjnym. Zresztą zwiastuny Hitchcocka pozostają wciąż istotne dla rozwoju branży reklamowej, wyrosłej wokół kultury produkcji filmów.

Zwiastun filmu Psychoza ${ }^{21}$, wybrany na potrzeby niniejszego tekstu jako studium przypadku, wszedł na ekrany w czasie, gdy emitowana była seria Alfred Hitchcock Presents. Interesująca jest korelacja popularności programu z pojawieniem się reżysera w zwiastunie. Obie produkcje łączyła też osoba Jamesa Allardice’a, który pisał dla Hitchcocka wprowadzenia do programu, jak i był autorem scenariusza zwiastuna. Zapowiedź kinowa Psychozy nie zawiera ani jednej sekundy zdjęć z filmu. Stephen Rebello przewrotnie nazywa ten zwiastun ,jednym wielkim oszustwem, radosną grą hochsztaplera"22, zauważając, że mimo ujawnienia przez reżysera sporej części fabuły, narracja zachowuje podstawowe zasady suspensu. Hitchcock, mówiąc publiczności, że stanie się coś strasznego, jednocześnie pozostawia jej oczekiwanie na rozwiązanie, przy czym sprytnie podrzuca mylące poszlaki, maskujące element zaskoczenia: odsuwa zasłonkę prysznica i odsłania postać blondynki, która wydaje się główną bohaterką - Janet Leigh, tymczasem okazuje się, że jest to druga gwiazda filmu - Vera Miles w peruce (to właśnie ta aktorka miała pierwotnie grać rolę Marion Crane) $)^{23}$.

Allardice obsadził Hitchcocka w roli „przewodnika po Domu Grozy”24, którego obecność w zwiastunie jest centralnym elementem metanarracji: osobiście oprowadza on widzów po planie filmowym, choć przechadzka ta wydaje się stanowić część tego, co zostało przedstawiane w filmie. Spacer Hitchcocka lokuje się w dziwnym kontekście czasowym: reżyser opisuje wydarzenia filmu tak, jakby działy się one w niedawnej przeszłości, a jednak nacisk w znacznym stopniu kładziony jest na przyszłe przeżycie tych

${ }^{21}$ Hitchcock nie figuruje w bazie IMDB jako reżyser tego trailera, informacje na temat autorstwa znajdują się jednak w przytaczanych pracach badaczy, m.in. u Kernan, Hesforda, a także w publikacji Stephena Rebello Alfred Hitchcock. Nieznana historia „Psychozy”, tłum. J. Rybski, Kraków 2013.

22 Ibidem, s. 253.

23 Zob. ibidem, s. 253-254.

24 Ibidem, s. 250. 
wydarzeń, a konkretnie - na przeżycie ich przez widownię. Obchód planu wpisuje się w trzy przestrzenie czasowe - teraźniejszości, przeszłości i potencjalnej przyszłości - stanowiąc przykład „krystalicznej” relacji czasowej, szczególnie istotnej dla formatu zwiastuna, który jest zdefiniowany poprzez jego ulotność i tymczasowość - jednoczesne spojrzenie wstecz i w przód ${ }^{25}$. Hitchcock dociera do słynnego domu rodzinnego Batesa i przypomina, że właśnie tam miały miejsce „najstraszniejsze wydarzenia”. Odwołuje się do filmu w czasie przeszłym jako do formy zapisu historycznego, budującego fikcyjną narrację reportażu z miejsca zbrodni, zaprzeczając semantycznemu czasowi przyszłemu zwiastuna ${ }^{26}$.

Barbara Klinger zauważa, że Hitchcock jako reżyser-gospodarz, prowadząc niemal autorski wywiad z samym sobą, pełni w zwiastunie funkcję performatywną. „Świadomie przejmuje tekst, aktywując i przywłaszczając jego elementy; aktywacja ta powoduje rozmycie granicy między tekstem a paratekstem, jeśli nie całkowite jej zatarcie"27. Jak z kolei zauważa Hesford, rola reżysera, jego afektywna obecność, jest dla widowni rozpoznawalnym przejściem do wnętrza filmu - do reprezentowanego przez niego gatunku, do jego stylu ${ }^{28}$. Hitchcock manipuluje kamerą, wciągając ją w opowieść dotyczącą - jak sam to ujął - „sceny zbrodni”. W trakcie spaceru zabiera kamerę na posesję i wreszcie do samego motelu, a następnie stwierdza: „Dzień dobry. Oto mamy tu mały spokojny motel. Schowany daleko od szosy i, jak widzicie, zupełnie niewinnie wyglądający, choć tak naprawdę stał się właśnie znany jako scena zbrodni" 29 . Reżyser brzmi jak emocjonalnie wycofany sprawozdawca sądowy lub detektyw relacjonujący obiektywnie wydarzenia; nie wchodząc w szczegóły, sugeruje, że miało tu miejsce coś strasznego. Tak naprawdę Hitchcock w ironiczny sposób raczej igra z emocjami widzów.

25 Zob. D. Hesford, op. cit., s. 21.

26 E. Gamaker, Opening the Paratext: The Hitchcock Trailer as Assertion of Authorship, „Open Screens” 2018, Vol. 1, DOI: 10.16995/os.8.

27 B. Klinger, Digressions at the Cinema: Reception and Mass Culture, „Cinema Journal" 1989, Vol. 28(4), s. 6; cyt. za: E. Gamaker, op. cit, s. 3.

28 Zob. D. Hesford, op. cit., s. 47.

29 „Psycho” (1960) Theatrical Trailer - Alfred Hitchcock Movie, https://www. youtube.com/watch?v=DTJQfFQ401I [dostęp 30.03.2020]. Wszystkie cytaty ze zwiastuna podaję za tym źródłem we własnym tłumaczeniu. 
Efekt retoryczny tego quasi-kryminalistycznego podejścia ma również wpływ na dziwne odczucie czasu w zwiastunie. Trailer wzmaga u publiczności oczekiwanie na wejście do kin Psychozy przez przedstawienie czasu przeszłego. W jakimś znaczeniu tego słowa wydarzenia filmu umiejscowione są w przeszłości; tak się też dzieje, jeśli chodzi o Hitchcocka, ponieważ to on jest ich autorem. Paradoksalnie, perspektywa zwiastuna powoduje, że widz wyczekuje na to, co się wydarzy, kieruje się ku przyszłości. Oko kamery w zwiastunie obejmuje te aspekty jednocześnie - przeszłość, teraźniejszość i przyszłość - dając niezwykle „krystaliczny” obraz. W tym kontekście nasuwa się myśl Deleuze’a, który dowodził, że „obraz jest kompozycją swego własnego »teraz«, a jednocześnie "przeszłości«, którą to konkretne »teraz« się zaraz stanie. Częścią składową teraźniejszości jest też nieokreślona przeszłość i przyszłość - to, co wirtualne" ${ }^{30}$.

Według Donato Totaro „ten obraz-kryształ (crystal-image), stanowiący kamień węgielny Deleuzjańskiego obrazu-czasu (time-image), jest ujęciem, które zlewa aspekt przeszły nagrywanego wydarzenia z aspektem teraźniejszym jego oglądania. Obraz-kryształ jest niepodzielną jednością obrazu rzeczywistego i wirtualnego" ${ }^{31}$. Ten wirtualny aspekt wyrazistego obrazu zawiera możliwość potencjalnej przyszłości, mającej źródło w teraźniejszości, a wirtualna rzeczywistość stanie się zarazem teraźniejszością, jak i przeszłością, kiedy zostanie częścią obrazu-kryształu. To, co wirtualne, przywołuje to, co mogłoby się stać i w rzeczy samej się stało, podczas gdy to, co rzeczywiste, przywołuje to, co zlokalizowane świadomie w przeszłości lub przyszłości ${ }^{32}$. Zwiastun stanowi granicę między dwoma stanami lub jak to ujął Totaro - „niezmienne lustro weneckie, dzielące teraźniejszość na dwa odmienne kierunki"33.

Przeniósłszy się do domu Batesów, reżyser wspomina:

30 D. Hesford, op. cit., s. 48.

31 D. Totaro, Gilles Deleuze's Bergsonian Film Project, „Offscreen” 1999, Vol. 3, No.3, http://www.horschamp.qc.ca/9903/offscreen_essays/deleuze2.html [dostęp 30.03.2020].

32 Zob. G. Deleuze, Kino: 1. Obraz - ruch. 2. Obraz-czas, tłum. J. Margański, Gdańsk 2008, s. 295-296.

33 D. Totaro, op. cit., s. 48. 
To na szczycie tych właśnie schodów miało miejsce drugie morderstwo. Wyszła [kobieta - przyp. A.G.] przez tamte drzwi i na górze natknęła się na ofiarę. Oczywiście w mgnieniu oka pojawił się nóż, ofiara błyskawicznie osunęła się i zwaliła z okropnym trzaskiem - myślę, że kręgosłup złamał się natychmiast po tym, jak uderzył o podłogę. Trudno opisać, to jak... To skręcenie... To... Nie będę się nad tym rozwodził.

Choć nasuwa się na myśl morderstwo, Hitchcock dba, by pojawiły się jedynie aluzje do jego pewnych aspektów: „pojawił się nóż”, ofiara „osunęła się i zwaliła”, „myślę, że kręgosłup złamał się...”. Jego relacja jest celowo niepełna, rwana; reżyser nie opisuje samego aktu zabójstwa ani nie podaje ciągu zdarzeń prowadzącego do śmierci ofiary na schodach. David Rodowick widzi w tej opowieści efekt uwolnienia czasu przez obraz-kryształ od konieczności podporządkowania się rytmowi akcji: „Jak już chronologia zostanie starta w pył, czas staje się rozproszony, tak jak wiele faset rozerwanego kryształu. Chronologia zostaje rozbita, szatkując przeszłość, teraźniejszość i przyszłość na osobne serie, nieciągłe i niewspółmierne" 34 .

Hesford dostrzega, że Hitchcock wykorzystuje wyjęte z kontekstu momenty afektywne („nóż”, „ofiara osunęła się”, „kręgosłup złamał się”), by uzyskać efekt retoryczny i metanarracyjny; przechodzi przez bezczasową diegezę, dokonując nieustannych aluzji do nieuchronności przyszłości wirtualnej, nadchodzącego przeżycia, co staje się częścią uroku obrazu ${ }^{35}$. Zanurzając się coraz bardziej szczegółowo w mrocznych aspektach filmu, w pokoju matki Normana Hitchcock mówi: „Oto pokój tej kobiety, wciąż [zachowany] w doskonałym stanie”. Jego komentarze sugerują stan, w jakim matka Normana znajduje się w kulminacyjnym momencie: „nie w pięknym stanie”. Hitchcock robi aluzję do jej działań, budując seksualne napięcie wokół kobiety, która w naszym mniemaniu jest morderczynią, napięcie, które w oczywisty sposób okaże się niewłaściwie ulokowane - Hitchcock podchodzi do łóżka i wskazuje na nie: „I odcisk jej postaci na łóżku, na którym kiedyś się kładła”. Podchodzi do szafki: „Myślę, że część jej ubrań wciąż jest w tej szafie”. Otwiera szafę, ale jej zawartość pozostaje dla publiczności niewidoczna, potem zagląda do środka i ukradkiem rzuca na

34 D. Rodowick, Gilles Deleuze's Time Machine, cyt. za: D. Hesford, op. cit., s. 49 .

${ }^{35}$ Ibidem. 
kamerę zagadkowe spojrzenia. Przechadzka Hitchcocka wyprowadza kamerę z domu Batesów i wprowadza ją do samego motelu. Reżyser udaje się do łazienki, w której wydarzyła się zbrodnia, i stwierdza: „No cóż, już to wszystko posprzątali. Duża różnica... Powinniście byli zobaczyć tę krew. Wszystko tu było... No cóż, to zbyt okropne, by to opisać. Okropne”. Kieruje się do ustępu: „A teraz powiem wam, że tu znaleziono niezwykle istotną wskazówkę”. Podnosi klapę od muszli klozetowej i wskazuje: „Tam na dole”. I znów jego słowa są podszyte niedopowiedzeniami, pełne uników i specyficznego humoru. Ten quasi-kryminalistyczny, iluzoryczny obiektywizm pęka z hukiem w ostatnim ujęciu zwiastuna. Hitchcock odsuwa zasłonę prysznica i odsłania kobietę, która stoi w brodziku i krzyczy z przerażenia.

Opowieść o świecie przedstawionym Psychozy jest nacechowana humorem i autotematyzmem, a to sprowadza narrację z powrotem do teraźniejszości: czy ta kobieta czekała pod prysznicem cały czas, kiedy reżyser się przechadzał? Co teraz z nią będzie? Poprzez głośne przywołanie nieuchronności jej losu, połączone z kwestią jej obecności w niedawnej, nieokreślonej przeszłości samego zwiastuna, Hitchcock samą opowieść czyni „krystaliczną"36.

Zdaniem Daniela Hesforda, w zwiastunie Psychozy opowieść stworzona jest z zasadniczo odmiennych momentów czasowych, a spaja ją to, czego w jej odczytaniu brakuje, czyli „wirtualna przestrzeń narracyjna” (virtual narrative space $)^{37}$. Ta niedopowiedziana przestrzeń narracyjna zwiastuna dodatkowo podtrzymuje uwagę i zainteresowanie odbiorcy. Istotna dla interpretacji tej kwestii jest teoria Davida Bordwella, według którego „fabuła (fabula) jest szablonem, który odbiorcy opowieści tworzą sobie poprzez założenia i implikacje. Jest to rozwijający się efekt wychwytywania sygnałów narracyjnych, nakładania schematów i hipotez, a także testowania tych ostatnich”38. Bordwell definiuje narrację jako „proces, w którym filmowy sjużet i styl współdziałają we wskazywaniu i ukierunkowaniu dokonywanej przez widza konstrukcji fabuły" ${ }^{39}$. Jak zauważa Hesford, Hitchcock ukierun-

36 Zob. ibidem, s. 51.

37 Ibidem, s. 50.

38 D. Bordwell, Narration in The Fiction Film, cyt. za: D. Hesford, op. cit., s. 52.

39 D. Bordwell, Narration in The Fiction Film, cyt. za: A. Helman, J. Ostaszewski, Historia myśli filmowej. Podręcznik, Gdańsk 2008, s. 318. 
kowuje widownię, przekazuje swą własną relację ze zdarzeń w dość figlarny, przewrotny sposób - jego obecność komplikuje zrozumienie opowieści, a zarazem zmienia oczekiwania względem zwiastuna jako reklamówki ${ }^{40}$.

Promocyjna obecność Hitchcocka stanowi świetny przykład nadawania zwiastunom marki przez przykładanie luminarskiej pieczęci. W opinii Hesforda „tożsamość Hitchcocka jako luminarza kina autorskiego przypomina o dialektycznej interakcji między sztuką a komercją, jego praktykę filmową można pojmować jako dialektykę wykorzystującą rozrywkę i ekspresyjne formy twórczości" ${ }^{31}$. Hitchcock jako reżyser kina autorskiego, zaangażowany jednocześnie w promocję własnej twórczości, umiejscawia zwiastun w komercyjno-artystycznym dyskursie. Jako nonkonformistyczny twórca znany był z dbałości o zachowanie pełnej kontroli artystycznej nad procesem powstawania swoich dzieł, zarówno filmów, jak i ich zwiastunów $^{42}$. W miarę wzrostu znaczenia Hitchcocka jako „reżysera-autora” wzrastał też jego wpływ na wymiar artystyczny materiałów promocyjnych. Jego niepowtarzalny, niejednoznaczny styl tworzenia, nadający kształt również zwiastunom, powodował, jak to ujął Elan Gamaker, że pozornie „zamknięte teksty”, niepoddające się w założeniu interpretacji, „otwierały się” na wielowymiarowe i wieloznaczne odczytanie. W ten sposób w zwiastunach Hitchcocka krzyżują się merkantylizm z ambicjami artystycznymi ${ }^{43}$.

Hitchcock postawił samego siebie w centrum swej aktywności artystycznej. Tworząc, kierował uwagę i zainteresowanie na własną osobę, na każdym kroku podkreślając i „autoryzując” wszystko, co robił. Jako jeden z pierwszych twórców kina od początku swej kariery świadomie kształtował swoją markę i rozpoznawalność. Jak zauważa Robert Kapsis, już w 1927 roku Hitchcock w liście otwartym do „London Evening News”, w odpowiedzi na pytania rzekomo zadane mu przez reportera, wykorzystał okazję, aby podkreślić swoje poglądy na temat reżysera jako „głównej siły w tworzeniu filmów”. List zdecydowanie sugerował, że już na tym wczesnym etapie

${ }^{40}$ D. Hesford, op. cit., s. 52.

${ }^{41}$ Ibidem, s. 27.

${ }^{42}$ M. Sella, The 150-Second Sell, Take 34?, „The New York Times Magazine”, 28.07.2002, http://www.nytimes.com/2002/07/28/magazine/the-150-second-sell-take-34.html [dostęp 30.03.2020].

${ }^{43}$ E. Gamaker, op. cit. 
kariery twórca Psychozy traktował siebie jako artystę i widział potencjał artystyczny w swoich filmach ${ }^{44}$.

Traktowanie dorobku reżysera, co odnotowuje Marcin Adamczak, jako spójnej stylistycznie i tematycznie, choć ewoluującej w czasie całości, a także postawienie osoby twórcy w centrum zainteresowania publiczności wpisuje się w model kina artystycznego, który „z perspektywy ówczesnego amerykańskiego przemysłu filmowego pozwalał przekonywać, że autorzy, artyści i sztuka są pojęciami, które wcale nierzadko można łączyć z hollywoodzkim systemem studiów"35.

„Autorstwo" postrzega się aktualnie w kontekście strategii marketingowej; autor jest utożsamiany $\mathrm{z}$ marką i w pewnym stopniu $\mathrm{z}$ gatunkiem ${ }^{46}$, tak więc jego osoba stanowi determinantę warunkującą decyzję widza kupującego bilet na równi $\mathrm{z}$ wyborem gatunku filmowego, tematyki czy aktorów ${ }^{47}$. „Autor jest też marką przyciągającą widzów, logo umieszczanym na plakatach filmu, wizerunkiem determinującym odbiór, znakiem jakości posiadającym symboliczną wartość, celebrity, funkcjonującym we współczesnej kulturze medialnej, i jest właściwą temu obiegowi kina taktyką redukcji rynkowego ryzyka"48.

Hesford, za Davidem Boydem i R. Bartonem Palmerem, zwraca uwage na współczesne znaczenie pojęcia „autora-marki” i wskazuje, że to właśnie Hitchcocka należy uznać za jednego z pierwszych reżyserów o statusie gwiazdy, nieustannie promującego siebie jako markę, by sprzedać swoje filmy i umocnić pozycję w branży. Dziś reżyser-gwiazda, poza wszystkim innym, pełni ważną rolę w sprzedawaniu swoich filmów, ponieważ gros publiczności częstokroć kieruje się bardziej nazwiskiem reżysera niż tytułem czy innymi elementami filmu ${ }^{49}$. Zwiększenie skali obecności reżyserów kina autorskiego wiąże się z niezwykle wyraźnym nadawaniem marki

${ }^{44}$ R. Kapsis, Hitchcock: The Making of a Reputation, Chicago 1992, s. 20.

45 M. Adamczak, Globalne Hollywood. Filmowa Europa i polskie kino po 1989 roku, Gdańsk 2010, s. 116 (tu i w kolejnych cytatach - kursywa oryginalna).

46 Zob. ibidem, s. 119.

47 Zob. ibidem.

48 Ibidem, s. 119-120.

49 Zob. D. Boyd, P. Barton Palmer, Introduction, [w:] After Hitchcock: Influence, Imitation and Intertextuality, cyt. za: D. Hesford, op. cit., s. 68. 
tekstom - obecnym dziesięciolecia później we współczesnej kulturze zwiastunowej - i napisom czołówkowym, takim jak: „nakręcony przez reżysera” (From the director of...) lub „nakręcony przez twórcę” (From the maker of...). Trend ten wprowadza narzędzia retoryczne - tak lingwistyczne, jak i filmowe - które odróżniają go od konwencjonalnych podejść komercyjnych, widywanych w reklamówkach innych marek ${ }^{50}$.

Autorski charakter zwiastunów Hitchcocka zawiera się nie tylko w stworzeniu interesujących, widowiskowych krótkich form, sygnowanych autorską marką Mistrza, ale także w otwarciu nowego pola do badań nad zwiastunami i wytyczeniu nowych dróg ich rozwoju. Schematyczna budowa zwiastuna (jako prostego zestawienia wybranych scen promowanego filmu, okraszonego komentarzem lektora i zawierającego najważniejsze informacje o obrazie, wśród których nazwisko reżysera nie zawsze jest na pierwszym planie) w przypadku omawianego trailera Psychozy została przełamana na wiele sposobów. Hitchcock nie pozostawia widzom najmniejszych wątpliwości, że to on jest centralną postacią zarówno filmu, jak i zwiastuna - autorem, którego twórczy potencjał wyraża się nie tylko w stworzeniu oryginalnego tekstu filmowego, ale także w promowaniu tego tekstu za pomocą paratekstu równie autorskiego, co sam film.

Zwiastuny Hitchcocka stanowią znakomity materiał dla zrozumienia potencjału „małego formatu” i możliwości jego rozwoju, a także ewentualnego wpływu na dyskurs filmoznawczy. Są widowiskowo bogate i interesujące. To chyba właśnie status Hitchcocka jako autora filmowego jest tu najistotniejszy, jeśli chodzi o jego wkład w rozwój formy zwiastuna i badania nam nią. Hitchcock nie postrzegał zależności zwiastuna od filmu (poprzednika) jako mankamentu, ale raczej jako szansę, którą można wykorzystać po to, by ugrać coś na polu tak artystycznym, jak i komercyjnym. Jego wkład w rozwój tego formatu daje podwaliny do rozważania zwiastuna jako pełnoprawnej części kultury filmowej.

W ostatnich latach obserwujemy trend, który wskazuje, że zwiastuny nabierają także wartości u widzów, są wyszukiwane, przechowywane i wielokrotnie oglądane $e^{51}$. Shaun Farrington - założyciel i dyrektor artystyczny

50 Zob. ibidem, s. 68-69.

51 Badania nad zwiastunami w kontekście zachowań odbiorczych publiczności podejmuje w swoich pracach Keith M. Johnston: The Coolest Way to Watch Movie 
Zealot, firmy kreatywnego marketingu, specjalizującej się w zwiastunach (Człowiek na linie [Man on Wire, reż. M. Marsch, 2008], Bękarty wojny [Inglourious Basterds, reż. Q. Tarantino 2009], Samotny mężczyzna [A Single Man, reż. T. Ford, 2009], Jak zostać królem [The King's Speech, T. Hooper, 2010]) - twierdzi, że zwiastuny „są bliskie jak nigdy wcześniej, traktowane jako forma sztuki na swych własnych prawach [...]. Już od lat mamy zrozumienie dla sztuki komercyjnej, [...] mówi się okay, to zostało stworzone $\mathrm{w}$ celu komercyjnym, ale zasługuje na swe miejsce w muzeum [...], to piękna forma działalności twórczej" 52 . Czy zatem twórcy świadomie czynią z trailera formę artystyczną? Czy może sama jego formuła gatunkowa burzy konwencjonalne struktury i problematyzuje odbiór przekazów audiowizualnych?

Mark Woolen - jeden z najbardziej uznanych montażystów zwiastunów w branży (Social Network [The Social Network, reż. D. Fincher, 2010], Dziewczyna $z$ tatuażem [The Girl With the Dragon Tattoo, reż. D. Fincher, 2011], Drzewo życia [The Tree of Life, reż. T. Mallick, 2011]) - twierdzi, że każdy znaczący producent powinien wyróżniać się swoją produkcją, a popularne chwyty stylistyczne, powszechnie stosowane w trailerach, zdążyły się już ograć i nie wywierają zamierzonego efektu na widzach, ważne jest zatem, żeby za każdym razem starać się na nowo, kreatywnie podchodzić do pracy produkcyjnej ${ }^{53}$. Woolen podkreśla znaczenie autorskiego charakteru zwiastunów produkowanych przez wybitnych twórców. Uważa, że reżyser powinien oddać w zwiastunie swój jasno rozpoznawalny styl, tak aby widzowie mogli na podstawie oglądu trailera założyć, co ich może czekać podczas projekcji filmu. Efekt ten może być osiągnięty wyłącznie w sytuacji, gdy estetyka zwiastuna odpowiada estetyce filmu. To indywidualne piętno reżyserskie nie tylko pomaga „sprzedawać” film w okresie okołopremierowym, ale sprawia, że zwiastun, sam w sobie, może stać się ponadczasowy. Przy niektórych filmach zwiastuny powinny być szczególnie bliskie styli-

Trailers in the World: Trailers in the Digital Age. „Convergence” 2008, Vol. 2; Coming Soon: The Selling of Hollywood Technology, London 2009.

52 Idem, Interview with Shaun Farrington, „Frames Cinema Journal” 2013, Vol. 3, http://framescinemajournal.com/article/1042/ [dostęp 30.03.2020].

53 Zob. J. Kehe, K.M. Palmer, Secrets of a Trailer Guru: How This Guy Gets You to the Movies, „Wired”, 18.06.2013, http://www.wired.com/2013/06/online-trailers-mark-woollen/ [dostęp 30.03.2020]. 
styce reżysera - dotyczy to zwłaszcza obrazów określanych przez podejście estetyczne ich reżyserów i ich artystyczne wybory ${ }^{54}$.

Niewątpliwie konwencjonalny zwiastun, z dynamicznym montażem, dramatycznymi scenami z filmu oraz efektownymi dialogami, wzmocniony atrakcyjną narracją lektorską i muzyką, również może się okazać skutecznym narzędziem marketingowym, ale z całą pewnością nie zostanie zapamiętany i nie będzie stanowił ciekawego przykładu kreatywności artystycznej. Specyfika marketingu filmowego plasuje się na granicy: film jest z jednej strony produktem komercyjnym, a z drugiej dziełem artystycznym, tak więc marketing filmowy nie ogranicza się do promowania filmu jako produktu, ale uwypukla także jego wartość artystyczną. W miarę komplikowania się medialnej technokultury niezbędne staje się uwzględnienie w planach marketingowych również tego czynnika.

\section{Bibliografia}

Charles Acland, Screen Traffic: Movies Multiplexes and Global Culture, Duke University Press, Durham 2003.

Marcin Adamczak, Globalne Hollywood. Filmowa Europa i polskie kino po 1989 roku. Przeobrażenia kultury audiowizualnej przełomu stuleci, Słowo/obraz terytoria, Gdańsk 2010.

Steven Blandford, Barry Grant, Jim Hillier, The Film Studies Dictionary, Hodder Headline Group, London 2001.

David Boyd, R. Barton Palmer, Introduction, [w:] After Hitchcock: Influence, Imitation and Intertextuality, eds. eidem, University of Texas Press, Austin 2006.

Claire Colebrook, Gilles Deleuze, Routledge, London 2002.

Timothy Corrigan, Auteurs and the New Hollywood, [w:] The New American Cinema, ed. J. Lewis, Duke University Press, Durham - London 1998.

Gilles Deleuze, Kino 1: Obraz - ruch. 2: Obraz - czas, tłum. J. Morgański, Słowo/ obraz terytoria, Gdańsk 2008.

Encyklopedia kina, red. T. Lubelski, wstęp A. Wajda, Biały Kruk, Kraków 2003.

Elan Gamaker, Opening the Paratext: The Hitchcock Trailer as Assertion of Authorship, „Open Screens” 2018, Vol. 1.

54 Ibidem. 
Gérard Genette, Paratexts. Thresholds of Interpretation, Basic Books, New York 1987. Jonathan Gray, Show Sold Separately: Promos, Spoilers and Other Media Paratexts, New York University Press, New York 2010.

Frederick L. Greene, Working in the World of Propaganda: Early Trailers \& Modern Discourses of Social Control, „Frames Cinema Journal” 2013, Vol. 3.

Frederick L. Greene, Keith M. Johnston, Ed Vollans, Would I Lie to You? Researching Audience Attitudes to, and Uses of, the Promotional Trailer Format, „International Journal of Media \& Cultural Politics” 2014, Vol. 10.

Mary Beth Haralovich, Cathy Root Klaprat, Marked Woman i Jezebel: widz w zwiastunie, tłum. P. Piekarski, [w:] Sztuka filmowej interpretacji, red. W. Godzic, Wydawnictwo UJ, Kraków 1990.

Daniel Hesford, The Art of Anticipation: The Artistic Status of the Film Trailer and its Place in a Wider Cinematic Culture, University of Edinburgh, Edinburgh 2013.

John Hill, Pamela Church Gibson, American Cinema and Hollywood: Critical Approaches, Oxford University Press, New York 2000.

Holly Howitt-Dring, Making Micro Meanings: Reading and Writing Microfiction, "Short Fiction in Theory and Practice" 2011, Vol. 1.

Keith M. Johnston, Interview with Shaun Farrington, „Frames Cinema Journal” 2013, Vol. 3, http://framescinemajournal.com/article/1042/.

Robert Kapsis, Hitchcock: The Making of a Reputation, University of Chicago Press, Chicago 1992.

Jason Kehe, Katie M. Palmer, Secrets of a Trailer Guru: How This Guy Gets You to the Movies, „Wired”, 18.06.2013, http://www.wired.com/2013/06/ online-trailers-mark-woollen/.

Lisa Kernan, Coming Attractions: Reading American Movie Trailers, University of Texas Press, Austin 2004.

Ira Konigsberg, The Complete Film Studies Dictionary, Bloomsbury, London 1998. Iwona Loewe, Parateksty $w$ telewizji, [w:] Pogranicza audiowizualności, red. A. Gwóźdź, TAiWPN Universitas, Kraków [cop. 2010].

Stephen Rebello, Alfred Hitchcock. Nieznana historia „Psychozy”, tłum. J. Rybski, Sine Qua Non, Kraków 2013.

Marshall Sella, The 150-Second Sell, Take 34?, „The New York Times”, 28.07.2002, http://www.nytimes.com/2002/07/28/magazine/28TRAILERS.html? pagewanted $=$ all.

Rafał Syska, Nie-film, nie-kino, „Ekrany” 2016, nr 5. 
Donato Totaro, Gilles Deleuze's Bergsonian Film Project: Part 1-2, „Offscreen” 1999, Vol. 3, No. 3.

François Truffaut, Hitchcock / Truffaut, współpraca H. Scott, tłum., oprac. i posłowie T. Lubelski, „Świat Literacki”, Izabelin [cop. 2005].

Michael Walker, Hitchcock's Motifs, Amsterdam University Press, Amsterdam 2005. Peter Wollen, Signs and Meaning in the Cinema, Indiana University Press, Bloomington 1969.

\section{Filmografia}

„Psycho” (1960) Theatrical Trailer - Alfred Hitchcock Movie, https://www.youtube. $\mathrm{com} /$ watch?v=DTJQfFQ401I [dostęp 30.03.2020].

Psychoza (Psycho), reż. Alfred Hitchcock, USA 1960.

\section{No Mere Advertising. The Artistic Status of Film Trailers (in the Context of Alfred Hitchcock's Psycho)}

Film trailers are usually dismissed as supplements to artistic texts which are the films themselves. Their 'fleeting' status reinforces the belief that a trailer is only meant to pave the way for the fully-fledged work. Trailers are of course a form of advertising, but at the same time they constitute short audiovisual works that can also be judged in artistic terms. This article is an attempt to demonstrate that the character of the trailers produced by director Alfred Hitchcock is expressed not only in the creation of spectacular short forms of advertising, signed by the author's brand of the 'master of suspense', but also in opening up a new field of research on the trailers themselves - as small audiovisual forms whose relation to the main text does not have to be at all simple or unambiguous - and in blazing new trails in their development. The trailer to Psycho (1960), which in itself is an artistically interesting statement, described in the article as a case study, reveals the elements that most fully present this director's approach to promotional texts. Different from a typical commercial, it can be seen in the context of the auteur theory, and perhaps also illustrates some of Gilles Deleuze's or David Bordwell's claims, which helps to place this ephemeral film form in a broader film discourse.

Keywords: Hitchcock, Psycho, film trailer, film advertising, paratext 